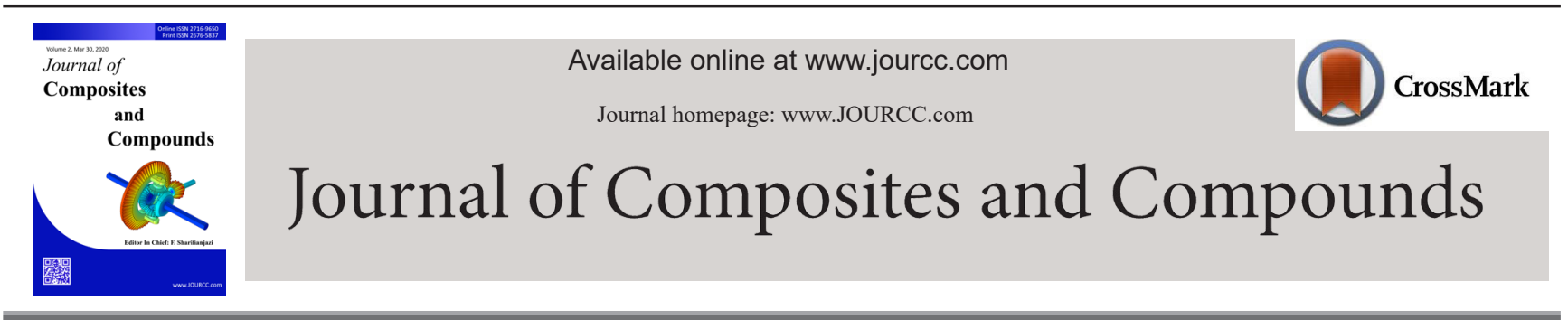

\title{
Photosensitive nanocomposites: environmental and biological applications
}

\author{
Ho Won Jangto ${ }^{a *}$, Amir Zareidoost ${ }^{b}$, Mostafa Moradi ${ }^{c}$, Aliasghar Abuchenari ${ }^{d}$, Ameneh Bakhtiari ${ }^{e}$, \\ Rasul Pouriamanesh ${ }^{f}$, Behzad Malekpouri ${ }^{g}$, Azadeh Jafari Rad ${ }^{h}$, Daruosh Rahban ${ }^{i}$ \\ ${ }^{a}$ Department of Materials Science and Engineering, Research Institute of Advanced Materials, Seoul National University, Seoul 08826, Republic of Korea \\ ${ }^{b}$ Faculty of Materials \& Metallurgical Engineering, Semnan University, Semnan, Iran \\ ${ }^{c}$ Department of Materials Science and Engineering, Sharif University of Technology, Azadi Street, Tehran, Iran \\ ${ }^{d}$ Materials Engineering, Shahid Bahonar University, Kerman, Iran \\ ${ }^{e}$ Department of Biology, Shahid Chamran University, Ahvaz, Iran \\ ${ }^{f}$ Mahshahr Pipe Mill Co. (MPM), Iran \\ ${ }^{g}$ Department of Materials Science and Engineering, Sharif University of Technology, Tehran, Iran \\ ${ }^{h}$ Department of Chemistry Omidiyeh Branch, Islamic Azad University, Omidiyeh, Iran \\ ${ }^{i}$ Department of Nanomedicine, School of Advanced MedicalTechnologies, Tehran University of Medical Science, Tehran, Iran
}

\begin{abstract}
A B S T R A C T
ART I C LE IN F O R M A T I O N

There has been an extensive investigation in the field of optical applications of nanocomposite materials. To

prepare photosensitive nanocomposites, an optically functional phase is embedded in a transparent, processable Received 17 September 2019

matrix. This provides the opportunity to utilize the optical properties in other forms including fibers and films, Received in revised form 27 November 2019 which are more technologically important. Due to expansion of optical materials applications, novel transparent Accepted 29 January 2020 materials and optically functional are required. Recent optical nanocomposites and their applications in different areas especially catalysis and drug delivery have been addressed in this paper.

Keywords:

(C)2020 JCC Research Group.

Peer review under responsibility of JCC Research Group

Catalysis

Cancer

Targeted drug delivery

Nanocomposites
\end{abstract}

Table of contents

1. Introduction. .50

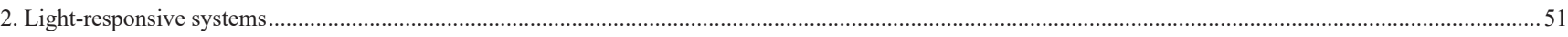

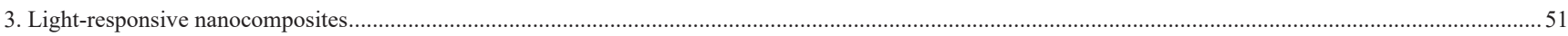

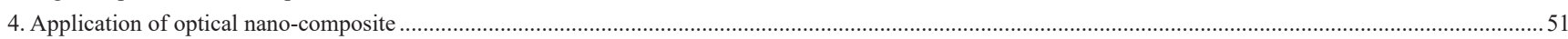

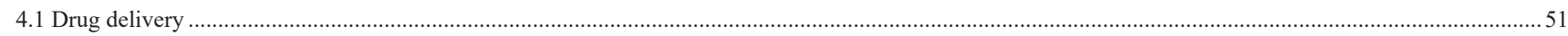

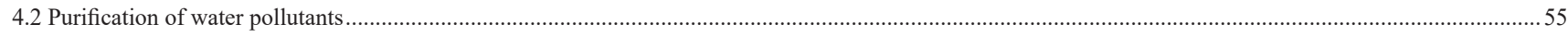

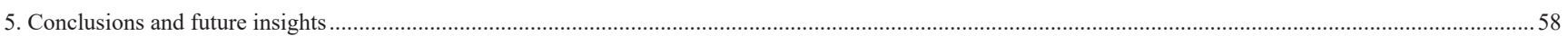

\section{Introduction}

Incorporation of semiconductor nanoparticles into ceramic, glass, and polymer matrix materials can provide various interesting optical properties such as nonlinearity, luminescence, fluorescence, and absorption $[1,2]$. In these nanocomposites, the matrix material acts as a stabilizer for the particles growth as well as their size, while the small particles improve the optical properties. Laser-active composites are produced by incorporation of ceramic nanoparticles of solid-state laser materials into polymer-based matrix leading to the formation of films amplified by solid-state laser, which were difficult to prepare traditionally. To retain the optical properties of polymer and glass matrices, optically functional small molecules and polymers can also be incorporated in these matrix materials. Potential applications of composites with nanostructures have led to development of transparent materials with excellent mechanical properties, magnetic properties, and unusually high RI [3].

*Corresponding author: Ho Won Jangtoa; E-mail: hwjang@snu.ac.kr 


\section{Light-responsive systems}

It is reported the UV light results in several disadvantages such as limited tissue penetration depth, and phototoxicity. This has made scientists to focus on providing nanoparticle systems that are light responsive in the visible region (400-700 nm), which leads to reduced phototoxicity. In this regard, the near-infrared light triggered DDSs have become increasingly important for enhancing the tissue penetration depth. Moreover, various studies have been performed about light-based advanced systems for photoacoustic and fluorescent imaging, as well as photothermal and photodynamic therapy $[4,5]$.

\section{Light-responsive nanocomposites}

In order to control the loading of guest substances, manage their release and enhance mechanical properties, a combination of inorganic substrates and light-sensitive polymers in one system has been favored in recent years [6-9]. Biocompatible and readily modifiable nanoparticles of $\mathrm{SiO}_{2}$ with new functionalities are promising for drug delivery applications [10]. Light-responsive nanoparticles of silica with average particle size of $70 \mathrm{~nm}$ have been produced by covalent conjugation of amino groups with molecules of photoactive o-nitro benzyl bromide on the particles surface [11]. These groups can be covalently bonded to drugs with hydroxyl, phosphate or carboxylic groups. The o-nitro benzyl bromide molecules are transformed into o-nitro benzaldehyde after irradiation of the resulting particles at $310 \mathrm{~nm}$. This leads to an irreversible cleavage of the bond between the drug and particle and subsequent release of the drug. The intracellular drug release could be externally controlled as because of the small size of these particles that enables their penetration into cells. Schematic of an optical nanocomposite [12] is illustrated in Fig. 1.

NIR light exposure results in photothermal effect and an increase in temperature in NIR-responsive systems leading to drug release [1315]. The temperature increase can simultaneously cause cell death called "photothermal treatment" [16, 17]. Other involved mechanisms are upconverting nanoparticles (UCNPs) and two-photon conversion [18]. These mechanisms are illustrated in Fig. 2 [19].

\section{Application of optical nano-composite}

It is expected that light-sensitive nano-composites attain widespread applications in the industrial and medical fields owing to their great potential. The applications of these light-sensitive nano-composites will be discussed in the following section.

\subsection{Drug delivery}

Intelligent drug delivery systems $[20,21]$ are able to modulate drug release proportionately to the specific stimuli intensity and can operate in closed or open circuit [22]. By automatic adjusting of the rate of drug release or switching the release on and off, self-regulated or closed-loop systems can detect specific variations in biological variables including concentration of some substances, temperature, or $\mathrm{pH}$ through activating or modulating the response. In open-loop systems, the response to particular an external stimulus is made by the drug release in a pulsing way. The drug release in these systems is proportional to the intensity and duration of each stimulus. This mode of release is not affected by the biological environment variables resulting in an explicit and precise triggering of the drug release. Upon the development of drug delivery systems responsive to heat, irradiation, magnetic or electrical field, ultrasound or compression, an exponential increase of investigations on polymeric and lipid-based architectures is observed in the last decade. The performance of photo-responsive nanocomposites in DDSs is depicted in Fig. 3 [23].

In a study, Zhang et al. [24] synthesized copper sulfide@polydopamine-folic acid/doxorubicin nanoparticles to produce a novel nanocomposite platform for chemotherapeutic and photothermal tumor-targeting treatment. Compared to $\mathrm{CuS} /$ polydopamine, the nanocomposite platform had higher efficiency of photothermal conversion and ultrahigh loading levels.

In another research by Cie et al. [25], the synergistic use of metal organic frameworks (MOFs) and UCNPs for the production of smart nanocomposites was investigated to be applied for photodynamic therapy against hypoxic tumors with high efficiency, which offers novel ways for MOF materials applications in effective cancer treatment. They believe that their research will provide new opportunities for the production of nanocomposites based on MOFs that integrates both multiple functionalities of encapsulated active parts and the synthetic tunability of MOFs. It is expected that the proposed strategy could reveal the extensive potential of MOFs for addressing challenges in other therapies.

Ghavaminejad et al. [26] proposed that the mussel-inspired nanocomposites they produced had controllable multidrug release and excellent heating properties, which can be offered as promising materials for cancer treatment due to the chemotherapy and photothermal therapy (PTT) synergistic effect. The nanocomposites were composed of a stimuli responsive hydrogel (poly(N-isopropylacrylamide) -co-polyacrylamide) incorporated with dopamine nanoparticles that is an effective photothermal agent. The loading drugs were doxorubicin (DOX) and bortezomib (BTZ).

Wang et al. [27] synthesized a novel photo-responsive nanocomposite composed of indocyanine green (ICG), DOX, and graphene oxide (GO)-polyamidoamine-pluronic F68 (PPF68). The nanocomposite was fabricated by cross-linking of graphene oxide with ICG and DOX and the formation of diselenide bond with PPF68. Contrary to commonly used nanomaterials, which are responsive to stimuli received from surrounding environmental, this synthesized nanocomposite responds to the reactive oxygen species (ROS) production via NIR by itself. The nanocomposites have the capability of selective accumulation in tumor cells. The lysosomal escape can occur due to enhanced ROS level and the high proton sponge effect resulting from polyamidoamine (PAMAM) The production of ROS by ICG can induce the diselenide bond cleavage under NIR laser irradiation, which triggers the decomposition inside tumor cell. As a result, before the drugs flow out by P-glycoprotein (P$\mathrm{gp}$ ) of multidrug resistant (MDR) tumor cells, the drug secretion could timely reach the therapeutic level. Finally, DOX nuclear trafficking is achieved to kill the MDR tumor cells in an effective way. Furthermore, the overall tumor therapeutic efficacy could be greatly enhanced with combining photothermal therapy and favorable on-demand chemotherapy. These NIR-responsive nanocomposites are shown to be successful in overcoming the MDR of tumor both in-vivo and in vitro, which provide promising novel strategies for clinical MDR cancer therapy.

Based on Nesic et al. [28] research, the nanocomposite based on nanoparticles of $\mathrm{TiO}_{2}$ as carrier and ruthenium complex with potential anticancer behavior have light controllable release characteristics. The prepared nanocomposite demonstrated biological activity and free radicals were generated. The free radicals are known as efficient tumor cell killers. The transition metal complex was released consistently from the surface demonstrating the controlled drug delivery system. Additionally, $\mathrm{Ru}$-complex secretion from the surface of $\mathrm{TiO}_{2}$ nanoparticles is believed to be dependent on the applied laser (green light) energy. Hence, these properties introduce these nanocomposite materials as suitable candidates for the photo-responsive chemotherapy. Fig 4 summarizes the results of the Hu et al. research [29]; they developed a novel, low-toxic, multifunctional QD-rGO nanocomposite to perform as a photothermal 

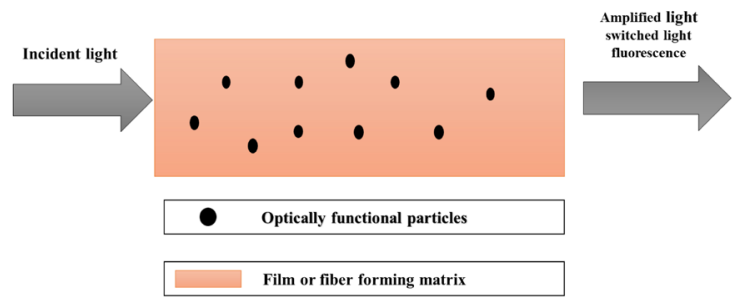

Fig. 1. Schematic of optical nanocomposite.

cancer-therapy agent in the NIR region and an imaging agent in the region of visible-light.

Chen et al. [30] also manufactured effective nanoplatforms of GO and reduced graphene oxide (rGO) nanomaterials for NIR-based PTT. In addition, many reports have demonstrated successful cancer therapy in-vivo and in-vitro with nanomaterials based on graphene as PTT agents, and also their combination with chemical conjugations, surface modification, ultrasound, imaging-guided, PDT, and chemotherapy to improve the therapeutic efficacy and tune their properties in biological systems [31]. In recent years, there have been novel therapeutic methods/ strategies and more functionalized nanocomposite based on graphene to improve the therapeutic efficiency of PTT. For modification of the nanocomposite materials based on graphene with highly efficient drug release, imaging-guided therapy, and multifunctional biological characteristics in a single system with the aim of achieving an efficient PTT and promoted cancer synergistic treatment, different inorganic nanoparticles and functional organic macromolecules have been conjugated on the graphene including magnetic iron oxide nanoparticles (IONPs), silica, $\mathrm{Au}$, and DNA.

Nanocomposite hydrogel prepared by Xu et al [32] showed a homogeneous 3D porous structure with steady, slow release rate of DOX during one month. The drug release from the prepared hydrogel had $\mathrm{pH}$-responsive property. This behavior was originated from the acid-labile hydrazone bond cleavage between adamantyl group and DOX, which occurs in acidic environment. The release of loaded drug from the nanocomposite can be accelerated by NIR irradiation. Graphene nanoribbons (GNRs) photothermal effect causes the collapse of the hydrogel networks controlled by the drug release. The excellent photothermal effect and biocompatibility of the prepared hydrogel were confirmed by the in vitro cytotoxicity test. Additionally, the mouse model study revealed that the hydrogel formed in-situ had promising tissue biocompatibility. According to the in vivo antitumor test, nanocomposite hydrogel showed its capacity for synergistic therapy of chemo-photothermal with less adverse effects as a result of efficient photothermal effect and long retention of drug in the tumor site. Thus, this injectable hydrogel, responsive to NIR and $\mathrm{pH}$, could be suggested as a promising material for a long-lasting drug release for chemo-photothermal combined cancer treatment.

Chen et al. [33], developed a mechanically strong and biocompatible nanocomposite hydrogel based on PNIPAM/clay/ carboxymethyl chitosan (CMCTs)/ genipin nanoparticles (GP) using free radical polymerization process with the help of the UV light irradiation, which was responsive to both temperature and $\mathrm{pH}$. To produce the nanocomposites, the natural molecular-genipin and clay were used as the cross-linkers. Under the optimum conditions and high UV light power, the hydrogels demonstrated a high value of tensile strength and the failure strain of about $137.9 \mathrm{kPa}$ and $446.1 \%$, respectively. The synthesized nanocomposite showed high-energy absorption in stretching processes. In the first loop at the room temperature, the nanocomposite was able to recover $76.1 \%$ of the adsorbed energy in $15 \mathrm{~min}$ after the removal of the load. In addition, the swelling/deswelling properties of the obtained nanocomposites were dependent on the content of GP, CMCTs, and clay. More-
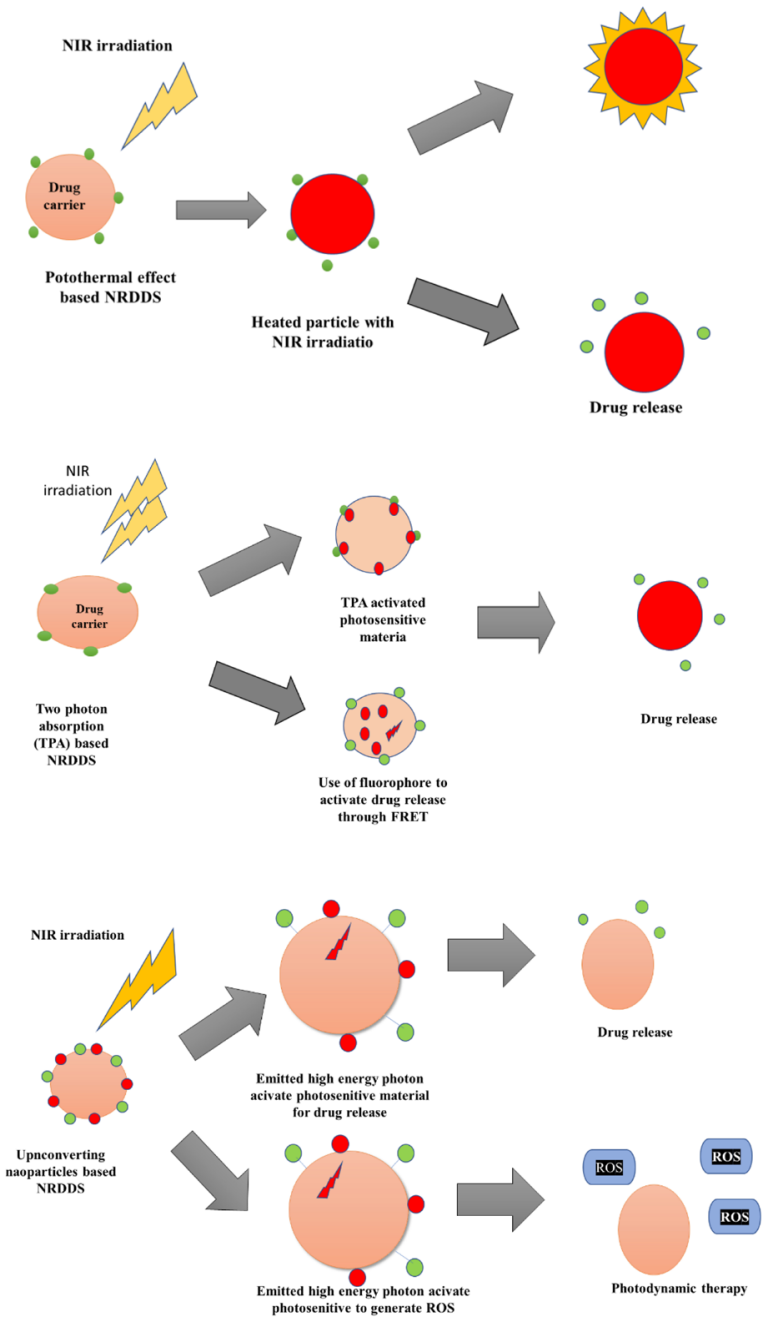

Fig. 2. A scheme of three mechanisms of NIR-responsive drug delivery systems (DDSs).

over, it was shown that the synthesized hydrogels had a controlled asprin release by regulating the density of crosslinks. According to the results, this promising property suggests these nanocomposites as proper carriers for controlled drug delivery applications.

A new light-responsive nanocomposite based on GO/Polyhedral oligomeric silsesquioxane (POSS) was synthesized by Teng et al. [34]. The synthesis was based on the reversible host-guest inclusion/exclusion method. Supramolecular assembly/disassembly property was observed upon visible and UV irradiation in graphene oxide nanosheets and POSS nanocage. Furthermore, the GO/POSS nanocomposites demonstrated a significant influence on oxygen permeability and good water dispersion in conventional films coated with polyvinyl alcohol (PVA) under different conditions of light irradiation. This could be helpful for development of smart materials as gas barriers in packaging.

To design tumor-targeted photo-controlled drug delivery, Luo et al. [35] developed a nanocomposite based on mesoporous silica/gold (MSN/Au). In the nanocomposites, gold nanoparticle (AuNP) and MSN acted as indicators and carriers, respectively. Photo-switchable azobenzene (Azo) moieties were employed to immobilize the MSN drug carrier. Poly (ethylene glycol) and a matrix metalloproteinase (MMP) substrate were used to modify the fluorescence-quenched gold nanoparticles. An $\alpha, \beta$ cyclodextrin dimer bridge connected the two types of nanoparticles. According to in vitro investigations, the specific interaction of the prepared nanocomposite with tumor region was observed overexpressing matrix metalloproteinase-2 (MMP-2) enabling the UV light guidance to release the entrapped drug. The integration of MSN-based drug carrier as well as the Au-based indicator could lead to the precise localization of 

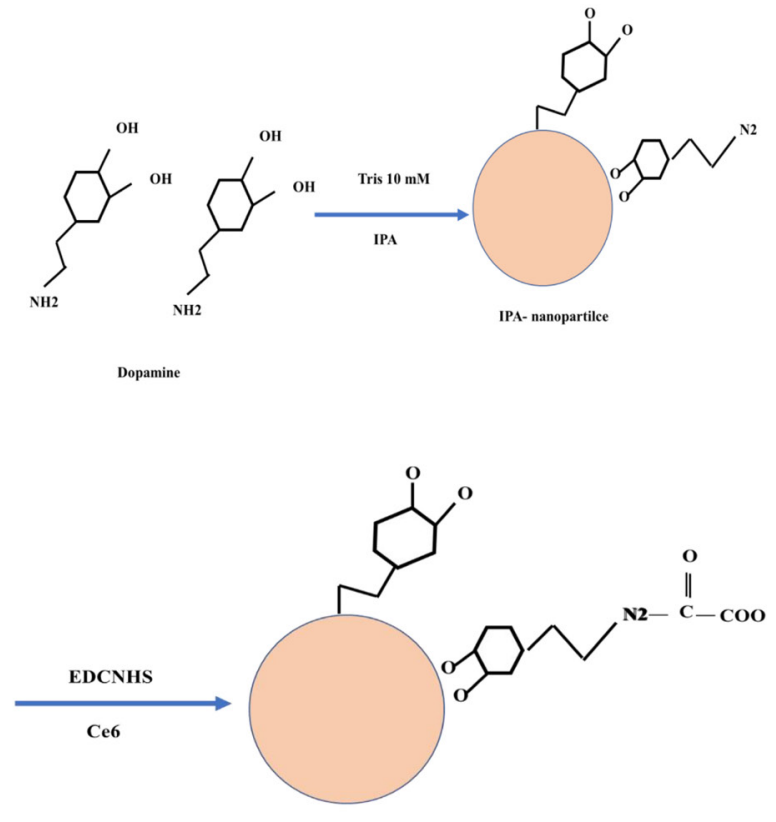

PDA-Ce6 nanosphere
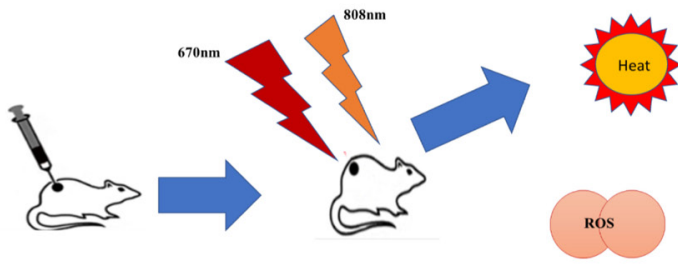

PTT

PDT

Fig. 3. Illustration of photodynamic therapy (PDT), using a combination of light and chemical photosensitizers (PS).

the released drug to tumor region and significant improvement of therapeutic efficacy.

Shi et al. [36] produced NIR-responsive nanocomposite hydrogels based on poly (N-isopropylacrylamide) (PNIPAM)/GO. To prepare the nanocomposites, they combined physically cross-linked graphene oxide nanosheets with chemically cross-linked small molecules. The excellent NIR response of the prepared hydrogels was originated from combining the polymeric networks of thermoresponsive PNIPAM and GO nanosheets. Incorporation of a low concentration of $\mathrm{N}, \mathrm{N}^{\prime}$-methylenebi$\mathrm{s}$ (acrylamide) (BIS) molecules for the formation of chemical cross-links in the hydrogels led to the formation of a relatively homogeneous structure with rare dense clusters containing chemical cross-links and flexible long polymer chains and, subsequently, the ultrahigh tensibility. Additionally, a further increase in hydrogel toughness could be achieved by hydrogen bond interactions and physical cross-linking generated among the amide groups existing in PNIPAM chains and oxidized groups of GO nanosheets. This synthesized nanocomposite with ultrahigh tensibility demonstrated fast, repeatable, and reversible NIR response that made them remarkably promising candidates for producing artificial muscles, smart actuators, and remote light-controlled devices.

As mentioned, graphene oxide and their nanocomposites are attracting attention in both photothermal therapy and drug delivery due to having high specific surface area as well as high NIR-optical absorption. In this regard, Li et al. [37] integrated (c,c,t-[Pt(NH3) $\left.\left.)_{2} \mathrm{Cl}_{2}(\mathrm{OH})_{2}\right]\right)$ complex and PEGylated nano-graphene oxide (PEG-NGO) into a single platform (PEG-NGO-Pt) to produce a multifunctional nanocomposite. The nanocomposite showed capability of synergic photothermal-chemotherapy and targeted drug delivery using NIR laser irradiation, and

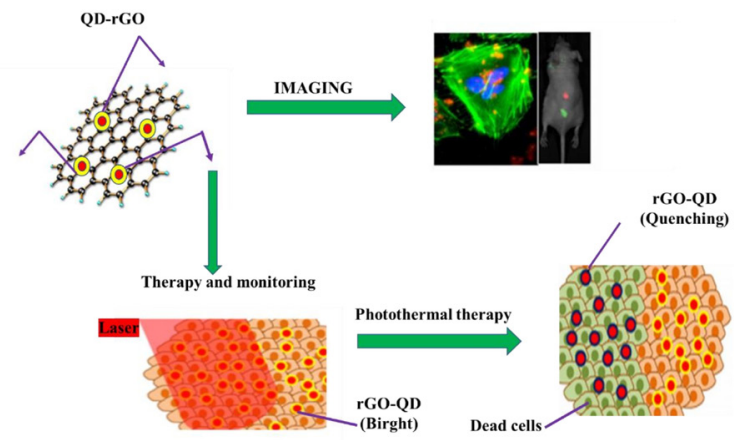

Fig. 4. rGO nanocomposites tagged with quantum dot (left) entered into targeted cancerous cells emit bright fluorescence from the quantum dots, (right); the absorption of NIR radiation by $\mathrm{rGO}$ and its conversion into heat, causing fluorescence reduction and cell death (Reproduced with permission [29]).

real-time monitoring with high therapeutic efficacy. The nanocomposite therapeutic influence on cancer therapy was improved by apoptosis and cell death. As a result of the high potential of specific tumor targeting at higher temperatures and the improved cisplatin cytotoxicity, the therapeutic efficacy improvement of the loaded drug accompanied by complete destruction of tumors was proved. Compared to photothermal or chemotherapy treatment alone, minimal systemic toxicity and no tumor recurrence were observed indicating the beneficial influences of GO and $\mathrm{Pt}$ (IV) integration for anticancer therapy.

Using the PEG double acrylates (PEGDA) macromers gelation, Xia et al. [38] constructed porous nanocomposite hydrogels based on silicon. Under NIR irradiation, photosensitysis of porous silicon nanoparticles (PSiNPs) with singlet oxygen was initiated. Sustained drug release with high efficiency, significant photothermal effect, excellent biodegradability, and strong fluorescence of multifunctional PSiNPs/PEGDA hydrogels were indicated. Eventually, NIR light induced the hydrogels in situ growth in tumor cells providing a remarkable localized prevention for the adherence, viability, and tumor cells migration. Hence, they proposed that the fabricated hybrid hydrogels could be potential material for local cancer treatment in clinical practice in the future.

Yang et al. [39] grafted lactose acid (LA) onto polydopamine (PDA)@cobalt phytate (CoPA) to produce a novel multifunctional nanocomposite for photothermal therapy and photothermal imaging of cancers. The role of PDA core was to provide a template for the CoPA formation. The dual photo-responsive abilities of CoPA shell included induction of singlet oxygen formation as well as in-situ production of $\mathrm{O}_{2}$ through catalyzing intracellular water splitting, which enhanced photodynamic therapy influence on cancer cells under laser irradiation. Moreover, the LA grafting provided the synthesized nanocomposites with the targeting ability to determine particular targeted cancer treatment. The excellent synergistic PDT and PTT effect of PDA@CoPA-LA nanoparticles demonstrated their potential in the clinic cancer therapy applications.

Using facile and scalable solvothermal method, Ma et al. [40] synthesized $\mathrm{CdS} / \mathrm{rGO}$ nanocomposites for efficient anticancer treatment. According to morphological analysis, $\mathrm{CdS} / \mathrm{rGO}$ nanoflakes were formed by firm attachment of the spherical $\mathrm{CdS}$ nanoparticles on the $\mathrm{rGO}$ thin sheets. The cell survival cytocompatibility of the $\mathrm{CdS} / \mathrm{rGO}$ nanomaterials obtained from the live-dead assay method was indicated to be above $95 \%$ revealing their suitability for the cancer treatment. The improvement of $\mathrm{CdS} / \mathrm{rGO}$ nanoflakes temperature profile under the NIR radiation accelerated the cancer cell death. It was suggested that the proposed nanocomposites with anticancer activity could provide opportunities in biomedicine research to produce efficient materials for clinical appli- 
cations.

In another study, Gorgizadeh et al. [41] synthesized $\mathrm{MnFe}_{2} \mathrm{O}_{4} / \mathrm{C}$ nanocomposite with uniform spherical particles and cracked surface with the average particle size of $221.6 \pm 22 \mathrm{~nm}$. Saturation magnetization, coercivity, and magnetic moment of $\mathrm{MnFe}_{2} \mathrm{O}_{4} / \mathrm{C}$ nanocomposite were $13.250 \mathrm{emu} \mathrm{g}-1,13.204 \mathrm{G}$, and 0.55 , respectively. Cubic spinel $\mathrm{MnFe}_{2} \mathrm{O}_{4}$ dots with the diameter of $2.1 \pm 0.6 \mathrm{~nm}$ were embedded in carbon entity. The nanocomposite acted as a new absorbing agent of both ultrasound (US) wave and $808 \mathrm{~nm}$ laser light in treatment of mice with melanoma tumor and $\mathrm{C} 540$ cancer cells. $\mathrm{MnFe}_{2} \mathrm{O}_{4} / \mathrm{C}$ nanocomposite can also be used in magnetic resonance imaging as a contrast agent. Although $\mathrm{MnFe}_{2} \mathrm{O}_{4} / \mathrm{C}$ showed relative biocompatibility, their effect on the tumor cells was negligible at US waves of $1.0 \mathrm{MHz}$ and $808 \mathrm{~nm}$ laser light. The activation of nanocomposites to kill the C540 cancer cells occurred at US waves along with the laser light at power densities of 1.0 and $0.5 \mathrm{~W} \mathrm{~cm}^{-2}$. At these power densities, cell viability upon irradiation of both US and the laser light in the presence of $25 \mu \mathrm{g} \mathrm{mL}-1$ nanocomposite reached $4.6 \%$ and 21.5 , respectively. Moreover, intratumoral injection of the nanocomposite accompanied by US and laser light irradiations indicated via histological analyses resulted in a deep tumor tissue necrosis. Its potential theranostic effect in nanomedicine is apparent owing to its SDT and PTT efficacies as well as a highly contrast induction in MRI.

Liu et al. [42] fabricated rGO-hybridized PEG smart hydrogel and optimized their $\mathrm{pH}$ and NIR-responsive drug release properties for cancer therapy. The reason for selecting rGO was to improve photothermal property of the hydrogel [43, 44]. The results of study by Tan et al. [45] demonstrated that the injectable Dox/celecoxib (Cel)/MOFs@Gel nanocomposite showed remarkable biological abilities such as enhanced biocompatibility, antitumor efficacy, and $\mathrm{pH}$-responsiveness suggesting this nanocomposite as an appropriate carrier for local oral cancer therapy.

Using NIR-responsive polymers (HAMAFA-b-DDACMM) coating on the nanoparticles of hollow mesoporous $\mathrm{SiO}_{2}$, which was modified by octadecyltrimethoxysilane (C18) (HMS@C18) through self-assembly, Lin et al. [46] fabricated novel multifunctional nanovehicles for cell imaging and tumor treatment. HMS@C18 was selected as the core due to enhancement of biological stability and the drug loading capacity; the loading efficiency of which was higher than $70 \%$. As a result of the light-responsive copolymers degradation under NIR light excitation at $800 \mathrm{~nm}$, the pre-loaded nanocomposites could release the drug. The correlation of the release efficiency with the light power and irradiation time was also indicated. Based on in vitro investigations, the cancer cells over-expressing FA receptor (FR (+)) like KB cells by endocytosis were easily targeted by the prepared nanocomposites. Additionally, strong fluorescence of the copolymer provided the ability to track the drug delivery process.

Wang et al. [47], integrated stimuli-responsive release property and magnetic targeting by the synthesis of a new smart core-shell drug delivery system using magnetic mesoporous $\mathrm{SiO}_{2}$, which was coated by light-responsive azobenzene derivatives with covalent grafting. The loaded molecule release in the mesopores was triggered by visible light irradiation.

In another research, Jiang et al. [48], synthesized composite nanoparticles of $\mathrm{Au} /$ mesoporous $\mathrm{SiO}_{2} /$ rhodamine $\mathrm{B}$ isothiocyanate. These nanoparticles with well-defined mesoporous structure were shown to be suitable for drug loading and they showed strong absorption of infrared surface plasmon for light-controlled drug delivery as well as photothermal cancer treatment; thus, they could be functionalized for fluorescence imaging. This new nanomaterial can open an avenue in chemotherapy of cancer by synergistic use of hyperthermia and cell imaging.

According to Dong et al. [49], core/shell nanoparticles of superparamagnetic $\mathrm{Fe}_{3} \mathrm{O}_{4} / \mathrm{Au}$ with tunable optical properties and sizes were developed by a facile seed-mediated growth method. For the synthesis of the nanoparticles, gold seed were formed and attached on the surface of the core by Au-S covalent bonding, which were created in a simultaneous reaction in the one-pot operation. This synthesized nanocomposite was proposed to deliver an enhanced capability of localized photothermal tumor treatment and MRI under NIR laser radiation.

In a study by Zhang et al. [50], DOX was loaded into nanospheres composed of UCNPs@mSiOz-poly(N-isopropylacrylamide-comethacrylic acid) (NIPAm-co-MAA). The prepared composite drug delivery system showed a significant improved drug release at low $\mathrm{pH}$ values and

Table. 1. Optical nano-composite applied in the field of drug delivery

\begin{tabular}{|c|c|c|c|}
\hline Author & Optical nano-composite & Application & Ref. \\
\hline Wang et al. & AuNR@SiOz/Ce@polydopamine@aptamer nano-composite & $\begin{array}{l}\text { Enhancing treatment of non-small cell lung } \\
\text { cancer }\end{array}$ & [55] \\
\hline Zhang et al. & $\mathrm{Se} @ \mathrm{SiO}_{2}-\mathrm{FA}-\mathrm{CuS}$ nanocomposites & Chemo-Photothermal Cancer Therapy & [24] \\
\hline Cai et al. & $\begin{array}{l}\text { UCNPs/MB@ zeolitic imidazolate framework (ZIF-8)@catalase smart } \\
\text { nanocomposite with core-shell structure }\end{array}$ & $\begin{array}{l}\text { Efficient } \mathrm{H}_{2} \mathrm{O}_{2} / \mathrm{NIR} \text {-responsive PDT agent for } \\
\text { hypoxic tumor cells treatment }\end{array}$ & [25] \\
\hline Ghavami Nejad et al. & Nanocomposite Hydrogel & Chemo-Photothermal Cancer Therapy & [26] \\
\hline Yu et al. & $\begin{array}{l}\text { Rattle-type gold nanorods@void@porous-SiO } 2 \text { (GVPSPR)-DOX/tetrade- } \\
\text { canol (TD) nanocomposites }\end{array}$ & Chemo-Photothermal Cancer Therapy & [56] \\
\hline Wang et al. & ICG/DOX/GO-PPF68 NIR-responsive nanocomposite & Clinical treatment of MDR cancer & [27] \\
\hline Nešić et al. & Nanocomposite system made of colloidal $\mathrm{TiO}_{2}$ & Potential controlled metallo-drug delivery & [28] \\
\hline Niu et al. & Polydimethylsiloxane (PDMS)/GNPs nanocomposites & drug-delivery, microswitches, and soft robotics & [57] \\
\hline Chen et al. & Graphene-derived nanocomposites & Photothermal therapy of tumor treatment & [30] \\
\hline $\mathrm{Xu}$ et al. & $\begin{array}{l}\text { (NIPAm-co- methacrylated poly- } \beta \text {-cyclodextrin (MPCD))/GNRs nano- } \\
\text { composite }\end{array}$ & Chemophotothermal synergistic cancer therapy & [32] \\
\hline Chen et al. & Nanocomposite double network PNIPAM/clay/CMCTs/GP & Controlled drug release of aspirin & [33] \\
\hline Teng et al. & GO-POSS nanocomposites & Host-guest inclusion / Oxygen permeability & [58] \\
\hline Luo et al. & Mesoporous silica/gold (MSN/Au) nanocomposite & Controlled drug delivery system & [35] \\
\hline Shi et al. & PNIPAM-GO nanocomposite & $\begin{array}{l}\text { Artificial muscles, smart actuators, and remote } \\
\text { light-controlled devices }\end{array}$ & [36] \\
\hline Li et al. & $\mathrm{Pt}(\mathrm{IV})$ complexes/PEGylated GO sheets multifunctional nanocomposite & $\begin{array}{l}\text { A synergistic effect in the therapeutic efficacy } \\
\text { improvement of Pt drug using combined che- } \\
\text { motherapy photothermal treatment }\end{array}$ & [37] \\
\hline
\end{tabular}




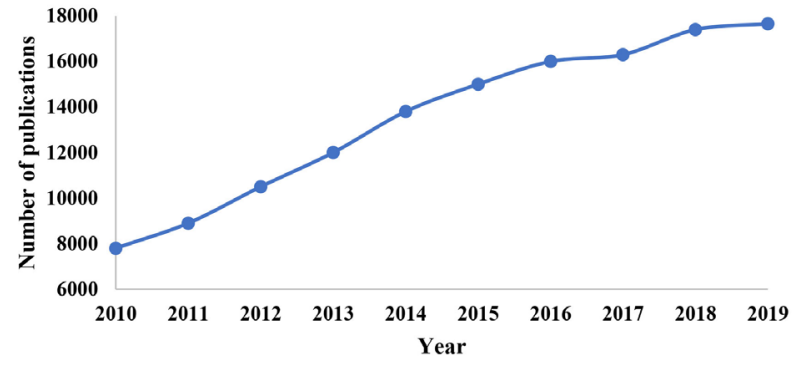

Fig. 5. Research reports focusing on optical nano-composite for purification of wastewater based on scholar-google database.

high temperature, which exhibited an apparent $\mathrm{pH} /$ thermo controlled drug release. These hybrid nanospheres could also be employed as biomonitors and bioimaging agents for tracking the drug release extent. Simultaneous stimuli-responsive drug delivery and imaging suggest these materials as a novel and reliable multifunctional nanocarriers.

Zhu et al. [51], synthesized a photo-responsive nanocomposite hydrogel based on PNIPAM/GO by in situ polymerization using $\gamma$-irradiation. Different levels of GO doping in the hydrogel led to a change in colors and phase-transition temperatures. The prepared hydrogel showed great photothermal properties as a result of the high value of optical absorbance of the GO. It was possible to control phase transitions by irradiation of NIR laser. The rate of NIR-induced temperature increased with GO loading amount and the temperature could be adjusted effectively by the duration of irradiation. It was proposed that the prepared nanocomposite with its excellent photothermal properties could be used in the biomedical applications, particularly as microfluidic devices and the easy synthetic method could be employed to synthesize other nanocomposites.

A novel Au nanorod (AuNRs)/NGO core/shell nanostructure was developed by Xu et al. [52] as an efficient agent for chemophotothermal cancer therapy. The role of NGO shells was to reduce the toxicity of AuNRs coated with surfactant and create anchor sites for conjugating the hyaluronic acid. Higher photothermal efficiency and the potential of targeting hepatoma Huh-7 cancer cells was achieved for the HA-conjugated nanocomposites (NGOHA-AuNRs) compared with AuNRs. DOX-loaded NGOHA-AuNR exhibited pH-responsive and triggered the drug-release with near-infrared light irradiation. In comparison with single photothermal therapy and chemotherapy, combined chemo-photothermal therapy showed higher rates of cancer cell death, with biosafety to nontargeting cells.

The PEG-GO/CuS nanocomposites synthesized by Bai et al. [53] showed excellent biocompatibility with high photothermal conversion efficiency, high anticancer DOX storage capacity, and capability of the tumor ablation. The DOX-loaded nanocomposites demonstrated higher toxicity compared to pure nanocomposites and free DOX under NIR laser irradiation, due to both cytotoxicity of DOX release triggered by light and photothermal ablation mediated by PEG-GO/CuS. According to mouse models investigation, the chemo-photothermal influence of DOX-loaded nanocomposites led to significant inhibition of mouse cervical tumor growth and an effective tumor cell reduction. In general, the synergetic therapy demonstrated higher therapeutic efficacy in comparison with photothermal and chemotherapy treatment alone.

A DNA cross-linked polymer was coated on $\mathrm{Au}-\mathrm{Ag}$ nanorods by Kang et al. [54] for a NRI-responsive drug delivery system. In order for gel scaffold to encapsulate anticancer drugs, DNA has been cross-linked for development of a sol-gel transition system based on polyacrylamide. By functionalization with targeting moieties like aptamers, nanohydrogel could specifically recognize tumor cells. The photothermal effect induced by NIR irradiation made the temperature of the surrounding gel increase rapidly, which led to the quick and controlled drug release with spatial/temporal resolution.

\subsection{Purification of water pollutants}

Due to increasing pace of industrialization, there are serious concerns about water pollution that creates major damages to human beings and microorganisms [59-61]. Several industries produce textile and other industrial dyes that can contaminate the fresh water. Moreover, due to containing highly toxic organic substances, these industrial dyes are considered as major water pollutants $[62,63]$. Thus, researchers around the world consider the removal of industrial organic contaminants as the most urgent action. One of the green approaches for complete elimination of organic contaminants is semiconductor photocatalysis. In these photocatalysts, solar energy sources can be used without creating any secondary pollution [64-66]. Metal oxides especially $\mathrm{ZnO}$ and $\mathrm{TiO}_{2}$ are commonly utilized photocatalysts for purification of wastewater owing to their strong photo-stability, non-toxicity, low-cost, and more availability [67]. Fig. 5 depicts the volume of research conducted in water purification field over the past decade.

Shi et al. [68], produced novel carbon nanotubes (CNTs) photocatalysts loaded with $\mathrm{Ag} / \mathrm{AgX}(\mathrm{X}=\mathrm{I}, \mathrm{Br}$, and $\mathrm{Cl})$ composite using a facile deposition-precipitation route with ultrasound. According to the results, the direct interfacial contact between CNTs and Ag/AgX nanoparticles was observed exhibiting superior visible light absorbance because of the Ag surface plasmon resonance (SPR). These produced composite photocatalysts were able to eliminate 2, 4, 6-tribromophenol (TBP) in aqueous phase. In comparison with pure CNTs or $\mathrm{AgX}$, the nanocomposites showed a significant improvement in visible light photocatalytic degradation efficiency because they effectively transfer electron from plasmon-excited $\mathrm{Ag}(0)$ and photoexcited $\mathrm{AgX}$ nanoparticles to CNTs. As a result, a prolonged photoholes lifetime and enhancement of the degradation efficiency could be achieved due to effective reduction of electron-hole recombination.

Using a hydrothermal process, Yue et al. [69] produced a visible-lightsensitive heterojunction photocatalyst with the formula of $\mathrm{Bi}_{2} \mathrm{MoO}_{6}$ $\mathrm{BiOCl}$. The as-prepared composite showed an irregular multi-plate structure composed of $\mathrm{BiOCl}$ and $\mathrm{Bi}_{2} \mathrm{MoO}_{6}$ nanoplates over each other. Compared to pure $\mathrm{Bi}_{2} \mathrm{MoO}_{6}$ and $\mathrm{BiOCl}$, the synthesized photocatalyst showed higher photocatalytic activity. $30 \% \mathrm{Bi}_{2} \mathrm{MoO}_{6}$ content was found to be optimal for the photocatalytic activity of the composites. The $\mathrm{O}_{2}$ and $\mathrm{OH}^{-}$had the main roles in rhodamine $\mathrm{B}(\mathrm{RhB})$ degradation through the $\mathrm{Bi}_{2} \mathrm{MoO}_{6}-\mathrm{BiOCl}$ composite.

In another study, Hamid et al. [70] synthesized a UV-visible light-responsive nanophotocatalyst composed of $\mathrm{TiO}_{2}$ and multiwalled carbon nanotube (MWCNT). The nanocomposites were produced via a modified sol-gel technique by functionalized MWCNTs and titanium isopropoxide as the initiating precursors. It was indicated that the surface of the MWCNTs were coated by $\mathrm{TiO}_{2}$ nanoparticles with a diameter of 10-20 nm. MWCNT/TiO 2 and pure $\mathrm{TiO}_{2}$ nanoparticles had the specific surface areas of 181 and $80 \mathrm{~m}^{2} / \mathrm{g}$, respectively. Therefore, photocatalytic performance of $\mathrm{MWCNT} / \mathrm{TiO}_{2}$ was better compared to pure $\mathrm{TiO}_{2}$ due to higher surface area leading to functioning as enhanced electron acceptors and electron-hole pair recombination inhibitors. Other reports have also highlighted the $\mathrm{CNT} / \mathrm{TiO}_{2}$ nanocomposites [71].

Photocatalytic performance under visible light radiation for the degradation of $\mathrm{RhB}$ by $\mathrm{g}-\mathrm{C}_{3} \mathrm{~N}_{4}-\mathrm{Fe}_{3} \mathrm{O}_{4}$ nanocomposites synthesized by Kumar et al. [72], exhibited remarkable improvement. Based on the obtained results, the nanocatalysts could be magnetically recovered and exhibited good recyclability while keeping their photocatalytic activity after six cycles. The high photocatalysts activity of the nanocomposite is because of improved charge-separation properties, high visible-light-absorption efficiency, and the large surface-exposure area. Additionally, the nanocomposites possessed superparamagnetic properties suggesting 
them as promising candidates for bionanotechnology and lithium storage capacity applications.

Research investigation on $\mathrm{Cu}$-doped $\mathrm{ZnO} /$ carbon nanotube nanocomposites by Ahmad et al. [73] showed effective MO bleaching out which was the indicator of a significant photocatalytic improvement over $\mathrm{ZnO}, \mathrm{ZnO} / \mathrm{CNTs}$, and $\mathrm{Cu}$-doped $\mathrm{ZnO}$ nanoparticles. Based on the results, the organic molecules were completely destroyed with color disappearance and the significant reduction in chemical oxygen demand of the treated effluent. The large surface area and excellent electrical properties of CNTs caused increased charge/separation efficiency, extended light absorbing capability, and higher dyes adsorptivity and, eventually, dramatic improvement of nanocomposite photoactivity.

Another visible-light-induced photocatalyst fabricated by a simple solution method is $\mathrm{Ag}_{2} \mathrm{O} / \mathrm{GO}$ nanocomposite. During $\mathrm{Ag}_{2} \mathrm{O} / \mathrm{GO}$ nanocomposite formation, negatively charged GO sheets interact electrostatically with positively charged $\mathrm{Ag}+$. The synthesized nanocomposites demonstrated promoted photocatalytic activity compared to $\mathrm{Ag}_{2} \mathrm{O}$ nanoparticles because of the enhanced electron-hole pair separation, smaller sizes of the $\mathrm{Ag}_{2} \mathrm{O}$ nanoparticles, and the enhanced adsorption capacity. The obtained results open new avenues to design photocatalysts with high efficiency for eliminating organic contaminants from water [73].

Tongon et al. [74] incorporated $\mathrm{Ag}$-doped $\mathrm{TiO}_{2}$ into mesostructured silica (MCM-41) by a microwave assisted sol-gel route for the preparation of a nanocomposite film with visible light responsive property. High photocatalytic properties and adsorbability of the $\mathrm{TiO}_{2}$ photocatalyst improved by MCM-41 and Ag were observed. Ag/Ti/Si with the composition of $0.1 / 1 / 2$ showed methylene blue (MB) decolorization efficiency equal to $30 \%$ under visible light, and $81 \%$ under UV light.

Ong et al. [74] prepared solvent exfoliated graphene (SEG)/ZnO photocatalysts using a simple chemical deposition-calcination method. The Reactive Black 5 (RB5) degradation of prepared nanocomposites were $97 \%$ and their rate constant was 0.0199 min-1 under an energy-saving light bulb which was indicated to be more than that of $\mathrm{ZnO}$ and SEG. The $\mathrm{ZnO}$ content of 69.0 wt. \% in the nanocomposite showed a significant improvement after graphene hybridization comparwd to pure $\mathrm{ZnO}$. The enhancement was reported to be due to electron-hole recombination retardation and effective dye sensitization by SEG as electron storage.

The $\mathrm{CdS} / \mathrm{La}_{2} \mathrm{Ti}_{2} \mathrm{O}_{7}$ photocatalyst nanocomposite was produced using a sonochemical coupled technique. This nanocomposite demonstrated a strong photocatalytic decomposition of methyl orange (MO) under visible light and UV radiation. The highest photocatalytic activity was obtained for the sample with $\mathrm{La}$ to $\mathrm{Cd}$ ratio of 1:3. The improved photocatalytic property of this nanocomposite was proposed to be related to the matched band potential of the two semiconductors and the layered structure of the nanocomposite [75].

Zhu et al. [76] used GO nanosheets to enwrap $\mathrm{Ag} / \mathrm{AgX}(\mathrm{X}=\mathrm{Cl}, \mathrm{Br})$ nanocomposites using a water/oil system. The prepared hybrid nanocomposites had the potential to be employed as a stable plasmonic photocatalyst for degradation of MO by visible-light radiation. Ag/AgX/GO nanocomposites displayed improved photocatalytic activities in comparison with the $\mathrm{Ag} / \mathrm{AgX}$ nanocomposites. Incorporation of $\mathrm{GO}$ nanosheets caused the retarded electron-hole pairs recombination, the facilitated charge transfer, the smaller $\mathrm{Ag} / \mathrm{AgX}$ nanoparticles, and the nice adsorptive capacity to $\mathrm{MO}$ molecules leading to promotion of photocatalytic performance of $\mathrm{Ag} / \mathrm{AgX} / \mathrm{GO}$. Based on these obtained results, developing graphene oxide-based plasmonic photocatalysts with high efficiency and stability would be possible.

In another research, nanocomposites of $\mathrm{SnS}_{2} / \mathrm{SnO}_{2}$ consisting of different $\mathrm{SnO}_{2}$ contents were produced by in situ hydrothermal oxidation of tin sulfide nanoparticles. According to the results, the synthesized nanocomposites with optimum amount of $\mathrm{SnO}_{2}$ showed remarkable photocatalytic stability as well as higher photocatalytic activity in comparison with $\mathrm{SnS}_{2}$ nanoparticles and the physical mixture of $\mathrm{SnO}_{2}$ and $\mathrm{SnS}_{2}$ nanoparticles. The high photocatalytic performances of $\mathrm{SnS}_{2} /$ $\mathrm{SnO}_{2}$ nanocomposites relates to bonding of $\mathrm{SnO}_{2}$ to $\mathrm{SnS}_{2}$ particles through which electron transfer at the interface could be facilitated and the self-agglomeration of the particles could be reduced [77].

Dong et al. [78] used an in situ photoactivated method to fabricate $\mathrm{AgBr} / \mathrm{Ag}$ nanocomposites in which Ag nanoparticles deposited evenly on the $\mathrm{AgBr}$ surface. Exposing to the irradiation of direct sunlight or cool daylight fluorescent lamp, the prepared nanocomposites revealed superior visible light photocatalytic performance against organic pollutant decomposition even under the diffuse indoor daylight. Moreover, the nanocomposites showed higher stability.

$\mathrm{TiO}_{2} /\left(\mathrm{TiO}_{2}-\mathrm{V}_{2} \mathrm{O}_{5}\right) /$ polypyrrole (PPy) nanocomposites were synthesized by Piewnuan et al. [79] using in situ polymerization. According to the results, the absorbance of the nanocomposites was higher than those of neat $\mathrm{TiO}_{2}$ and $\mathrm{TiO}_{2} / \mathrm{PPy}$ due to the reduction in the band gap energy of the materials. The nanocomposite catalytic activity was also continued in the dark. The mentioned behaviors are caused by capability of the polymer to act as a binder in the system and the energy storage ability of $\mathrm{V}_{2} \mathrm{O}_{5}$.

$\mathrm{Gu}$ et al. [80] incorporated reduced graphene oxide in $\mathrm{N}$-doped $\mathrm{TiO}_{2}\left(\mathrm{~N}-\mathrm{TiO}_{2}\right)$ as well as $\mathrm{V}$ co-doped $\mathrm{TiO}_{2}\left(\mathrm{~N}, \mathrm{~V}-\mathrm{TiO}_{2}\right)$ using a hydrothermal method. Both nanocomposite exhibited superior visible light photocatalytic performance compared to $\mathrm{N}, \mathrm{V}-\mathrm{TiO}_{2}$ and $\mathrm{N}-\mathrm{TiO}_{2}$. The reasons for such enhancement included minimizing the photoinduced electrons and holes recombination, high light absorption intensity, more excited states, and improvement of pollutants adsorption under visible light irradiation.

Pakula et al. [81] synthesized metal/ poly(methylmethacrylate) (PMMA) nanocomposites with light-controlled conductance switching property. The nanocomposites preparation was carried out by physical vapor deposition of $\mathrm{Pt}$ and Au clusters on azo-dye doped poly(methylmethacrylate) thin film. Functionalizing the azo groups with branches and tails caused high dye concentrations, which enhanced solubility. Under alternating irradiation of blue light and UV, a complete reversible optical switching of the absorption bands of the nanocomposites was observed.

Graphene quantum dots (GQDs) [82], functionalized by polyethylenimine (GQD-PEIs) nanocomposites were produced by Liu et al. [83] using hydrothermal method. Subsequently, by the amidation reaction of the PEI moieties with isobutyric anhydride, isobutyric amide (IBAm) groups were anchored on the functionalized GQD. The prepared nanocomposites was responsive to temperature, $\mathrm{pH}$, loaded organic guests, and inorganic salts. The modulation of cloud point temperature (Tcp) of the composites in aqueous solutions was reported to be done by altering the the inorganic salts type, $\mathrm{pH}$, the inorganic salts concentration, loaded organic guests, and the number of IBAm units in the nanocomposites. It was indicated that the nanocomposites were photoluminescent, and outside stimuli did not influence their maximum emission wavelengths. A negligibly influence of polar aspirin guest, $\mathrm{pH}$, and traditional salting-out anions such as $\mathrm{SO} 42-$ and $\mathrm{Cl}-$ on emission intensities were observed. It was also verified that the aspirin guest with relative polarity was absorbed by PEI-IBAm shell, while, the PBA guest with relative hydrophobicity was adsorbed by the GOD core. The guest release rate varied below and above Tcp.

Ren et al. [84] developed a graphene (GR)-CdS nanocomposite using a hydrothermal route in which the GR scaffold closely enwrapped $\mathrm{CdS}$ ingredients. They reported that incorporation of two-dimensional GR scaffolds to CdS microspheres had significant influence on hybrid nanocomposites properties including morphology, electronic and optical nature of the nanocomposite. The selective organic transformation results showed that the synthesized nanocomposite could be used as a visible-light-activated photocatalyst for efficient benzyl alcohol oxidation to 


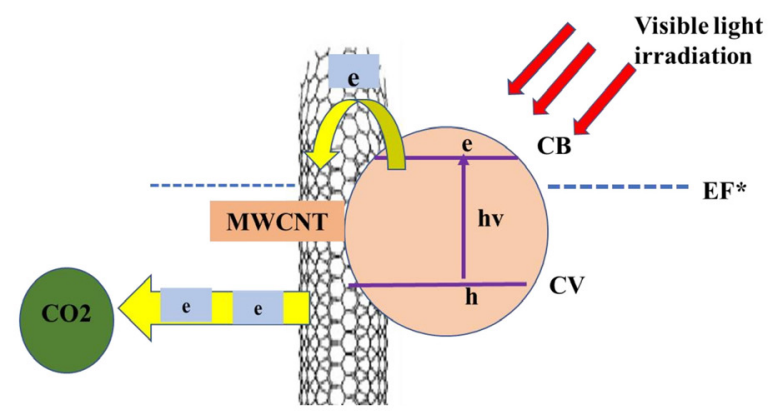

Fig. 6. MWCNT/ $/ \mathrm{TiO}_{2}$ core-shell nanocomposites.

benzaldehyde at ambient temperature. The combined influence of high electron conductivity and improved light absorption intensity of GR incorporated to remarkably improve the photocatalytic activity of the nanocomposites. These factors increased the lifetime of electron-hole pairs generated by light irradiation and facilitated charge separation. The research could provide the information for production of narrow bandgap semiconductor or GR hybrid nanocomposites applicable for a wide range of photocatalysis.

In a study conducted by Fernández et al. [85], Au nanorods (NRs) were coated by thermoresponsive poly(N-isopropylacrylamide) microgel shells. The investigations by optical extinction measurements and simultaneous laser-heating revealed that the Au cores could be simultaneously utilized for sensitive optical reporting of the microgel state and fast optothermal manipulating (switching) with the possibility of external control in a reversible manner.

Kong et al. [86] functionalized $\mathrm{TiO}_{2}$ nanoparticles with antifouling ethylene glycol dimethacrylate and biocidal 2-(tert-butylamino)ethyl methacrylate containing nontoxic secondary amine. Compared to pure $\mathrm{TiO}_{2}$ nanoparticles, core/shell nanoparticles showed higher photocatalytic antibacterial characteristics due to the synergetic antibacterial activity of light-driven biocidal polymer shell as well as $\mathrm{TiO}_{2}$ core. The prepared nanocomposites showed high antimicrobial efficiency of $95.7 \%$ for gram-positive S. aureus in the dark condition. Moreover, in comparison with pristine $\mathrm{TiO}_{2}$ nanoparticles, the nanocomposite demonstrated enhanced inhibition of bacterial growth during UV irradiation.

Woo et al. [87] reported the improved photoluminescence of layered nanocomposites consisting of $\mathrm{Sr}_{2} \mathrm{SiO}_{4}$ :Eu green phosphor core, multishell of $\mathrm{CdSe} / \mathrm{CdS} / \mathrm{CdZnS} / \mathrm{ZnS}$ red quantum dots, and thermo-curable resin. Two kinds of mixed and layered composite were produced, and the layered structure was found to be more effective compared to the mixed structure in terms of thermal loss, PL decay, and PL intensity. Moreover, by using the layered nanocomposite for preparing white light emitting diodes, the value of color rendering index increased to 88.4 and brightness enhanced by $37 \%$ in comparison with the mixed one.

Choi et al. [88], fabricated a dual-responsive nanocomposite including two noble metal nanoparticles and two polymer brushes and reported that they exhibited a significant improvement in selectivity for determining various liquids in comparison with a single-responsive LSPR sensor. Two hydrophilic and hydrophobic polymer brushes provided the dual-responsive LSPR sensor, which showed different response according to the interaction degree among the surrounding liquids and the polymer brushes. Additionally, the accurate estimation of the mixing ratio of two solvents, suggesting the dual-nanocomposite LSPR sensor as in situ process monitoring platform.

Chaengchawi et al. [89] synthesized a visible-light responsive nanocomposite of $\mathrm{CdS} / \mathrm{ZnO}$ as a photocatalyst. The obtained results demonstrated that the $\mathrm{ZnO}$ to $\mathrm{CdS}$ ratio had a significant effect on photocatalytic activity among which the highest photocatalytic performance was related to the mole ratio of 1:4 exhibiting higher activity compared to pure $\mathrm{ZnO}$ and $\mathrm{CdS}$. A novel $\mathrm{ZnO}-\mathrm{TiO}_{2}$ nanocomposite was also proposed by Haghighatzadeh et al. [90].
Nanocomposites with the composition of $\mathrm{TiO}_{2-x} \mathrm{~N}_{y} / \mathrm{Ag}-\mathrm{PbMoO}_{4}$ were produced using sonochemical technique. In comparison with $\mathrm{Ag}-\mathrm{PbMoO}{ }_{4}$ and $\mathrm{TiO}_{2-x} \mathrm{~N}_{y}$, photoinactivation of green tide (Tetraselmis suecica) of the synthesized nanocomposites was improved under simulated solar light. The nanocomposites were able to remove $100 \%$ of Tetraselmis suecica after 25 minutes. By inhibition of electron-hole recombination, the charge transfer was facilitated leading to enhancement of the nanocomposite photocatalytic activity [91].

In a study carried out by Pirhashemi et al. [92], the $\mathrm{ZnO} / \mathrm{Ag} / \mathrm{Ag}$ ${ }_{2} \mathrm{WO}_{4}$ nanocomposites exhibited good photocatalytic activity for $\mathrm{RhB}$ degradation. This enhancement was due to the heterojunctions formation among the counterparts and the surface plasmon resonance effect of Ag, which resulted in effective suppression of photogenerated charge carriers' recombination.

A novel nanocomposite for photocatalytic degradation of organic pollutants composed of $\mathrm{Ag} / \mathrm{CeO}_{2}$ was produced by Saravanakumar et al. [93] using hydrothermal method. The nanocomposite showed superior activity with the ability to degrade the RhB dye in 70 minutes, under visible light irradiation. Due to producing a large amount of $\mathrm{OH}$ radicals, the photocatalytic degradation enhanced. As a result of the lower charge carriers' recombination, the nanocomposite efficacy was much higher compared to pure $\mathrm{CeO}_{2}$. The surface plasmon resonance effect of $\mathrm{Ag}$ nanoparticles is a reason for the high photocatalytic activity of nanocomposites.

According to Ahmad et al. [94] study, the incorporation of GO in $\mathrm{CdO} / \mathrm{GO}$ nanocomposites improved the organic dyes photocatalytic degradation due to provision of more active sites available in high surface area. Highest MB degradation of $95 \%$ was achieved for the composition of $3.3 \% \mathrm{GO}$ after 35 minutes irridation in comparison with $\mathrm{CdO}$ and other compositions. GO inhibits the electron-hole pair recombination, extends the light absorption range, and increase the adsorbability of the catalysts, which leads to photocatalytic efficiency improvement of $\mathrm{CdO} / \mathrm{GO}$ nanocomposite. It was proposed that these nanomaterials have the potential to be employed for organic pollutants degradations from wastewater.

Hybrid nanocomposite photocatalysts of $\mathrm{CuO}(\mathrm{x}) / \mathrm{SmFeO}_{3}$ were prepared by Behzadifaed et al. [95]. Because of larger separation efficiency of photoinduced electron-hole pair, the $\mathrm{CuO}(10 \mathrm{wt} \%) / \mathrm{SmFeO}_{3}$ electrode showed the photocurrent of approximately 2 times more than that of the $\mathrm{CuO}$ and $\mathrm{SmFeO}_{3}$. The highest photocatalytic efficiency of $65 \%$ and the photocatalytic activity of $100 \%$ were achieved under visible light radiation for $\mathrm{RhB}$ dye degradation exhibiting the existence of both photocatalytic mechanisms and Fenton-like oxidation. Due to being highly active and stable, they suggested the prepared hybrid photocatalyst as a potential material for industrial water treatment.

According to a study by Gan et al. [96], $\mathrm{CoFe}_{2} \mathrm{O}_{4}$ incorporated Ag${ }_{3} \mathrm{PO}_{4}$ nanocomposites with core-shell structure were synthesized using a precipitation method. According to the results, the $\mathrm{CoFe}_{2} \mathrm{O}_{4}$ nanoparticles incorporation narrowed the $\mathrm{Ag}_{3} \mathrm{PO}_{4}$ band gap. The core-shelled structured nanocomposites showed superior efficiency of dyes degradation under the tungsten halogen lamp light in comparison with pristine $\mathrm{Ag}_{3} \mathrm{PO}_{4}$. Additionally, the nanocomposites exhibited good recycling stability for the dyes photocatalysis degradation and were magnetically separable. Overall, this research offers a new nanocomposite with the capability of photocatalytic degradation of organic contaminants present in wastewater, while does not introduce secondary pollutant into the system.

Using ultrasonic-irradiation echnique, Mousavi et al. [97] fabricated g- $\mathrm{C}_{3} \mathrm{~N}_{4} / \mathrm{Fe}_{3} \mathrm{O}_{4} / \mathrm{Ag}_{3} \mathrm{PO}_{4} / \mathrm{AgCl}$ nanocomposites which had promising photocatalytic activity under visible-light irradiation. This nanocomposite demonstrated higher photocatalytic performance in degradation of $\mathrm{RhB}$ than that of $\mathrm{g}-\mathrm{C}_{3} \mathrm{~N}_{4}$. Because of significant saturation magnetization of 8.78 emu.g-1, it was possible to easily separate the photocatalyst from 
the solution after treatment by an external magnetic field. It was found that driving the degradation reaction is caused mostly by holes as main active species.

The $\mathrm{NiFe}_{2} \mathrm{O}_{4} / \mathrm{MWCNTs} / \mathrm{ZnO}$ nanocomposite was also fabricated with solar radiation driven photocatalic activity. Upon solar radiation, the prepared nanocomposite showed a significant enhancement in photocatalytic activity in comparison with $\mathrm{ZnO}$ and $\mathrm{NiFe}_{2} \mathrm{O}_{4}$ for degradation of $\mathrm{MB}$ dye in aqueous solutions. Recombination retardation of electron-hole pairs caused higher charge separation efficiency leading to improved photocatalytic activity. They reported that the apparent rate constant (kapp) of the MB degradation in 300 minutes using $\mathrm{ZnO}, \mathrm{NiFe}_{2} \mathrm{O}_{4}$, and $\mathrm{NiFe}_{2} \mathrm{O}_{4} / \mathrm{MWCNTs} / \mathrm{ZnO}$ were $0.002,4.12857 \mathrm{E}-4$, and $0.00438 \mathrm{~min}-1$, respectively. The magnetic properties of the nanocomposite provide the possibility of its separation and re-usability after degradation experiments. It was suggested that the prepared nanocomposite can be utilized as a solar radiation driven photocatalyst [98].

Paul et al. [99] reported the preparation of a $\mathrm{MnMoO}_{4} / \mathrm{NiFe}_{2} \mathrm{O}_{4}$ nanocomposite using co- hydrothermal and precipitation routes. The synthesized photocatalyst exhibited 95\% Basic Fuchsin removal efficiency and superior photocatalytic activity with $96 \%$ efficiency for different dyes including Methyl Violet (MV), RhB, and MB degradation in aqueous medium under visible light radiation. Increased agglomerated forms of the synthesized $\mathrm{MnMoO}_{4} / \mathrm{NiFe}_{2} \mathrm{O}_{4}$ nanocomposites were observed in the spent photocatalyst.

Nickel tungstate/tin phthalocyanine (NiWO4/SnPc) nanocomposite produced by the solvent evaporation technique showed the enhancement of NiWO4 photocatalytic property for Rhodamine blue degradation [100].

Core-shell nanocomposites consisted of $\mathrm{MWCNT} / \mathrm{TiO}_{2}$ demonstrated that their photoactivity in the visible light was remarkably improved with extension of absorption edge to the region related to visible light. These nanocomposites showed continuous transformation of $\mathrm{CO}_{2}$ into methane at atmospheric pressure and under the irradiation of low power visible light. After 6 hours of irradiation, the maximum methane production of ca. $0.17 \mu \mathrm{mol} / \mathrm{g}$-catalyst $/ \mathrm{h}$ was achieved. Fig 6 depicts the model used in this article [101]

\section{Conclusions and future insights}

Using light-sensitivity as an attractive property for preparation of advanced DDS that can modulate the rate and site externally. In order to optimize the therapeutic efficiency and reproducible release profiles of the light responsive materials various approaches is currently investigated. In order to use the light-sensitive DDS for clinical practices, considerable additional efforts are required regarding specific aspects including: (1) In vivo analysis of newly developed delivery systems. In order to make progress toward clinical applications, supplementary in vivo studies must be carried out in addition to in vitro investigations. (2) Specialized equipment to provide sufficient irradiation intensity for targeting specific region while does not alter surrounding tissues. Because the human body is to relatively impermeable to the light, applicability of the visible light UV-sensitive DDS is limited to treatments of the skin surface layers. Feasible alternatives to light/UV-sensitive DDS appear to be NIR-sensitive light materials and NIR lasers. (3) Design and fabrication of new biocompatible materials for extending the range of light-sensitive polymers and lipids which meet the needs for developing safe products. For example, azobenzene groups are considered as toxic materials by the FDA which constrains the application of such DDS [102].

It is expected that novel nanocomposites with various chemical designs will offer an attractive and insightful approaches to overcome the problems of both ingestion and identification, enhance intertumoral accumulation and decrease the drugs toxicity to produce high-sensitive materials with high efficiency.

\section{Acknowledgments}

The authors received no financial support for the research, authorship and/or publication of this article.

\section{Conflict of Interest}

All authors declare no conflicts of interest in this paper.

\section{REFERENCES}

[1] S. Ravi, F. Winfred Shashikanth, Magnetic properties of Mo-doped TiO2nanoparticles: A candidate for dilute magnetic semiconductors, Materials Letters $264(2020) 127331$

[2] S. Ananthakumar, J. Ramkumar, S.M. Babu, Semiconductor nanoparticles sensitized TiO2 nanotubes for high efficiency solar cell devices, Renewable and Sustainable Energy Reviews 57 (2016) 1307-1321.

[3] L.L. Beecroft, C.K. Ober, Nanocomposite materials for optical applications, Chemistry of materials 9(6) (1997) 1302-1317.

[4] H. Chen, Y. Zhao, Applications of Light-Responsive Systems for Cancer Ther-anostics, ACS Applied Materials \& Interfaces 10(25) (2018) 21021-21034.

[5] R. Bisht, J.K. Jaiswal, I.D. Rupenthal, Nanoparticle-loaded biodegradable light-responsive in situ forming injectable implants for effective peptide delivery to the posterior segment of the eye, Medical Hypotheses 103 (2017) 5-9.

[6] K. Haraguchi, Nanocomposite hydrogels, Current Opinion in Solid State and Materials Science 11(3-4) (2007) 47-54.

[7] S. Sortino, Nanostructured molecular films and nanoparticles with photoac-tivable functionalities, Photochemical \& Photobiological Sciences 7(8) (2008) 911924.

[8] E. Johansson, E. Choi, S. Angelos, M. Liong, J.I. Zink, Light-activated func-tional mesostructured silica, Journal of sol-gel science and technology 46(3) (2008) 313-322.

[9] A.K. Agegnehu, C.-J. Pan, M.-C. Tsai, J. Rick, W.-N. Su, J.-F. Lee, B.-J. Hwang, Visible light responsive noble metal-free nanocomposite of V-doped TiO2nanorod with highly reduced graphene oxide for enhanced solar $\mathrm{H} 2$ production, International Journal of Hydrogen Energy 41(16) (2016) 6752-6762.

[10] I.I. Slowing, B.G. Trewyn, S. Giri, V.Y. Lin, Mesoporous silica nanoparti-cles for drug delivery and biosensing applications, Advanced Functional Materials 17(8) (2007) 1225-1236.

[11] D.Y. Wu, S. Meure, D. Solomon, Self-healing polymeric materials: a review of recent developments, Progress in polymer science 33(5) (2008) 479-522.

[12] R.M. Abozaid, Z.Ž. Lazarević, I. Radović, M. Gilić, D. Šević, M.S. Rabaso-vić, V. Radojević, Optical properties and fluorescence of quantum dots CdSe/ ZnS-PMMA composite films with interface modifications, Optical Materials 92 (2019) 405-410.

[13] H.U. Kim, Y.H. Roh, M.S. Shim, K.W. Bong, Microfluidic fabrication of fatty alcohol-based microparticles for NIR light-triggered drug release, Journal of In-dustrial and Engineering Chemistry 80 (2019) 778-783.

[14] L.-t. Liu, M.-j. Chen, H.-1. Yang, Z.-j. Huang, Q. Tang, C.-f. Chow, C.-b. Gong, M.-h. Zu, B. Xiao, An NIR-light-responsive surface molecularly imprinted polymer for photoregulated drug release in aqueous solution through porcine tissue, Materials Science and Engineering: C 106 (2020) 110253.

[15] Z. Liu, J. Shi, Y. Wang, Y. Gan, P. Wan, Facile preparation of pyrenemethyl ester-based nanovalve on mesoporous silica coated upconversion nanoparticle for NIR light-triggered drug release with potential monitoring capability, Colloids and Surfaces A: Physicochemical and Engineering Aspects 568 (2019) 436-444.

[16] M.S. Noh, S. Lee, H. Kang, J.-K. Yang, H. Lee, D. Hwang, J.W. Lee, S. Jeong, Y. Jang, B.-H. Jun, Target-specific near-IR induced drug release and photother-mal therapy with accumulated $\mathrm{Au} / \mathrm{Ag}$ hollow nanoshells on pulmonary cancer cell membranes, Biomaterials 45 (2015) 81-92.

[17] J. Wang, Y. Liu, Y. Ma, C. Sun, W. Tao, Y. Wang, X. Yang, J. Wang, NIRActivated Supersensitive Drug Release Using Nanoparticles with a Flow Core, Advanced Functional Materials 26(41) (2016) 7516-7525.

[18] G. Yang, J. Liu, Y. Wu, L. Feng, Z. Liu, Near-infrared-light responsive nanoscale drug delivery systems for cancer treatment, Coordination Chemistry Reviews 320 (2016) 100-117.

[19] A. Raza, U. Hayat, T. Rasheed, M. Bilal, H.M.N. Iqbal, "Smart" materi-alsbased near-infrared light-responsive drug delivery systems for cancer treat-ment: A review, Journal of Materials Research and Technology 8(1) (2019) 1497-1509. [20] X. Li, D. Liu, Y. Wang, S. Xu, H. Liu, Water dispersive upconversion 
nanopar-ticles for intelligent drug delivery system, Colloids and Surfaces A: Physicochem-ical and Engineering Aspects 555 (2018) 55-62.

[21] H.M. Lin, W.K. Wang, P.A. Hsiung, S.G. Shyu, Light-sensitive intelligent drug delivery systems of coumarin-modified mesoporous bioactive glass, Acta Biomaterialia 6(8) (2010) 3256-3263.

[22] S. Sershen, J. West, Implantable, polymeric systems for modulated drug deliv-ery, Advanced drug delivery reviews 54(9) (2002) 1225-1235.

[23] D. Zhang, M. Wu, Y. Zeng, L. Wu, Q. Wang, X. Han, X. Liu, J. Liu, Chlorin e6 conjugated poly (dopamine) nanospheres as PDT/PTT dual-modal therapeu-tic agents for enhanced cancer therapy, ACS applied materials \& interfaces 7(15) (2015) 8176-8187.

[24] S.-Q. Zhang, X. Liu, Q.-X. Sun, O. Johnson, T. Yang, M.-L. Chen, J.-H. Wang, W. Chen, CuS@PDA-FA nanocomposites: a dual stimuli-responsive DOX delivery vehicle with ultrahigh loading level for synergistic photothermal-chemotherapies on breast cancer, Journal of Materials Chemistry B 8(7) (2020) 1396-1404. [25] H.-J. Cai, T.-T. Shen, J. Zhang, C.-F. Shan, J.-G. Jia, X. Li, W.-S. Liu, Y. Tang, A core-shell metal-organic-framework (MOF)-based smart nanocomposite for ef-ficient NIR/H2O2-responsive photodynamic therapy against hypoxic tumor cells, Journal of Materials Chemistry B 5(13) (2017) 2390-2394.

[26] A. GhavamiNejad, M. SamariKhalaj, L.E. Aguilar, C.H. Park, C.S. Kim, $\mathrm{pH} / \mathrm{NIR}$ light-controlled multidrug release via a mussel-inspired nanocomposite hy-drogel for chemo-photothermal cancer therapy, Scientific reports 6(1) (2016) $1-12$

[27] M. Wang, J. Wu, Y. Li, F. Li, X. Hu, G. Wang, M. Han, D. Ling, J. Gao, A tumor targeted near-infrared light-controlled nanocomposite to combat with multidrug resistance of cancer, Journal of Controlled Release 288 (2018) 34-44.

[28] M. Nešić, I. Popović, A. Leskovac, Z. Šaponjić, M. Radoičić, M. Stepić, M. Petković, Testing the photo-sensitive nanocomposite system for potential controlled metallo-drug delivery, Optical and Quantum Electronics 48(2) (2016) 119. [29] S.H. Hu, Y.W. Chen, W.T. Hung, I.W. Chen, S.Y. Chen, Quantum-dot-tagged reduced graphene oxide nanocomposites for bright fluorescence bioimaging and photothermal therapy monitored in situ, Advanced materials 24(13) (2012) 17481754

[30] Y.-W. Chen, Y.-L. Su, S.-H. Hu, S.-Y. Chen, Functionalized graphene nano-composites for enhancing photothermal therapy in tumor treatment, Advanced drug delivery reviews 105 (2016) 190-204.

[31] A. Kazemzadeh, M.A. Meshkat, H. Kazemzadeh, M. Moradi, R. Bahrami, R. Pouriamanesh, Preparation of graphene nanolayers through surfactant-assisted pure shear milling method, Journal of Composites and Compounds 1(1) (2019) 22-26.

[32] X. Xu, Z. Huang, Z. Huang, X. Zhang, S. He, X. Sun, Y. Shen, M. Yan, C. Zhao, Injectable, NIR/pH-responsive nanocomposite hydrogel as long-acting implant for chemophotothermal synergistic cancer therapy, ACS applied materials \& interfaces 9(24) (2017) 20361-20375.

[33] Y. Chen, G. Song, J. Yu, Y. Wang, J. Zhu, Z. Hu, Mechanically strong dual responsive nanocomposite double network hydrogel for controlled drug release of asprin, Journal of the mechanical behavior of biomedical materials 82 (2018) 61-69.

[34] Z. Teng, B. Wang, Y. Hu, D. Xu, Light-responsive nanocomposites combin-ing graphene oxide with POSS based on host-guest chemistry, Chinese Chemical Letters 30(3) (2019) 717-720.

[35] G. Luo, W. Chen, H. Jia, Y. Sun, H. Cheng, R. Zhuo, X. Zhang, An indica-tor-guided photo-controlled drug delivery system based on mesoporous silica/ gold nanocomposites, Nano Research 8(6) (2015) 1893-1905.

[36] K. Shi, Z. Liu, Y.-Y. Wei, W. Wang, X.-J. Ju, R. Xie, L.-Y. Chu, Near-infrared light-responsive poly ( $\mathrm{N}$-isopropylacrylamide)/graphene oxide nanocomposite hy-drogels with ultrahigh tensibility, ACS applied materials \& interfaces 7(49) (2015) 27289-27298.

[37] J. Li, Z. Lyv, Y. Li, H. Liu, J. Wang, W. Zhan, H. Chen, H. Chen, X. Li, A ther-anostic prodrug delivery system based on Pt (IV) conjugated nano-graphene oxide with synergistic effect to enhance the therapeutic efficacy of Pt drug, Biomaterials 51 (2015) 12-21

[38] B. Xia, W. Zhang, J. Shi, J. Li, Z. Chen, Q. Zhang, NIR light-triggered gelling in situ of porous silicon nanoparticles/PEGDA hybrid hydrogels for localized combinatorial therapy of cancer cells, Journal of Applied Polymer Science 136(17) (2019) 47443

[39] Z. Yang, X. Liu, X. Wang, P. Wang, S. Ruan, A. Xie, Y. Shen, M. Zhu, 4-in1 phototheranostics: PDA@CoPA-LA nanocomposite for photothermal imaging/ photothermal/in-situ O2 generation/photodynamic combination therapy, Chemical Engineering Journal 387 (2020) 124113.

[40] Y. Ma, F. Yan, L. Liu, W. Wei, Z. Zhao, J. Sun, The enhanced photo-thermal therapy of Surface improved photoactive cadmium sulfide (CdS) quantum dots en- trenched graphene oxide nanoflakes in tumor treatment, Journal of Photochemistry and Photobiology B: Biology 192 (2019) 34-39.

[41] M. Gorgizadeh, N. Behzadpour, F. Salehi, F. Daneshvar, R.D. Vais, R. Nazari-Vanani, N. Azarpira, M. Lotfi, N. Sattarahmady, A MnFe2O4/C nanocom-posite as a novel theranostic agent in MRI, sonodynamic therapy and photother-mal therapy of a melanoma cancer model, Journal of Alloys and Compounds $816(2020) 152597$.

[42] W. Liu, X. Zhang, L. Zhou, L. Shang, Z. Su, Reduced graphene oxide (rGO) hybridized hydrogel as a near-infrared (NIR)/pH dual-responsive platform for combined chemo-photothermal therapy, Journal of colloid and interface science 536 (2019) 160-170.

[43] R. Klajn, Spiropyran-based dynamic materials, Chemical Society Reviews 43(1) (2014) 148-184

[44] W. Wu, A.D.Q. Li, Optically switchable nanoparticles for biological imaging, Nanomedicine 2(4) (2007) 523-531.

[45] G. Tan, Y. Zhong, L. Yang, F. Ren, Metal-Organic Frameworks@, Thermo-sensitive Hydrogel as Injectable Implant for Dual Drug Synergistic Oral Cancer Therapy, Available at SSRN 3458140

[46] Q. Lin, C. Bao, S. Cheng, Y. Yang, W. Ji, L. Zhu, Target-activated coumarin phototriggers specifically switch on fluorescence and photocleavage upon bonding to thiol-bearing protein, Journal of the American Chemical Society 134(11) (2012) 5052-5055.

[47] Y. Wang, B. Li, L. Zhang, H. Song, L. Zhang, Targeted delivery system based on magnetic mesoporous silica nanocomposites with light-controlled release character, ACS applied materials \& interfaces 5(1) (2013) 11-15.

[48] Z. Jiang, B. Dong, B. Chen, J. Wang, L. Xu, S. Zhang, H. Song, Multifunc-tional $\mathrm{Au} @ \mathrm{mSiO}$ /rhodamine B isothiocyanate nanocomposites: cell imaging, photocontrolled drug release, and photothermal therapy for cancer cells, small 9(4) (2013) 604-612

[49] W. Dong, Y. Li, D. Niu, Z. Ma, J. Gu, Y. Chen, W. Zhao, X. Liu, C. Liu, J. Shi, Facile synthesis of monodisperse superparamagnetic Fe3O4 core@ hybrid@ Au shell nanocomposite for bimodal imaging and photothermal therapy, Advanced materials 23(45) (2011) 5392-5397.

[50] X. Zhang, P. Yang, Y. Dai, P.a. Ma, X. Li, Z. Cheng, Z. Hou, X. Kang, C. Li, J. Lin, Multifunctional Up-converting nanocomposites with smart polymer brushes gated mesopores for cell imaging and thermo/pH dual-responsive drug controlled release, Advanced Functional Materials 23(33) (2013) 4067-4078.

[51] C.H. Zhu, Y. Lu, J. Peng, J.F. Chen, S.H. Yu, Photothermally sensitive poly (N-isopropylacrylamide)/graphene oxide nanocomposite hydrogels as remote light-controlled liquid microvalves, Advanced Functional Materials 22(19) (2012) 4017-4022

[52] C. Xu, D. Yang, L. Mei, Q. Li, H. Zhu, T. Wang, Targeting chemophotother-mal therapy of hepatoma by gold nanorods/graphene oxide core/shell nanocom-posites, ACS applied materials \& interfaces 5(24) (2013) 12911-12920.

[53] J. Bai, Y. Liu, X. Jiang, Multifunctional PEG-GO/CuS nanocomposites for near-infrared chemo-photothermal therapy, Biomaterials 35(22) (2014) 58055813.

[54] H. Kang, A.C. Trondoli, G. Zhu, Y. Chen, Y.-J. Chang, H. Liu, Y.-F. Huang, $\mathrm{X}$. Zhang, W. Tan, Near-infrared light-responsive core-shell nanogels for targeted drug delivery, ACS nano 5(6) (2011) 5094-5099.

[55] Y. Wang, L. Wang, L. Guo, M. Yan, L. Feng, S. Dong, J. Hao, Photo-re-sponsive magnetic mesoporous silica nanocomposites for magnetic targeted cancer therapy, New Journal of Chemistry 43(12) (2019) 4908-4918.

[56] Y. Yu, M. Zhou, W. Zhang, L. Huang, D. Miao, H. Zhu, G. Su, Rattle-type gold nanorods/porous-SiO2 nanocomposites as near-infrared light-activated drug delivery systems for cancer combined chemo-photothermal therapy, Molecular pharmaceutics 16(5) (2019) 1929-1938

[57] D. Niu, W. Jiang, H. Liu, T. Zhao, B. Lei, Y. Li, L. Yin, Y. Shi, B. Chen, B. Lu, Reversible bending behaviors of photomechanical soft actuators based on graphene nanocomposites, Scientific reports 6 (2016) 27366

[58] S. Tang, B. Xuan, X. Ye, Z. Huang, Z. Qian, A modular vaccine develop-ment platform based on sortase-mediated site-specific tagging of antigens onto virus-like particles, Scientific reports 6(1) (2016) 1-9.

[59] H. Wang, L. Zhang, Z. Chen, J. Hu, S. Li, Z. Wang, J. Liu, X. Wang, Semi-conductor heterojunction photocatalysts: design, construction, and photocatalytic performances, Chemical Society Reviews 43(15) (2014) 5234-5244

[60] F. Correia, M. Calheiros, J. Marques, J. Ribeiro, C. Tavares, Synthesis of $\mathrm{Bi} 2 \mathrm{O} 3 / \mathrm{TiO} 2$ nanostructured films for photocatalytic applications, Ceramics Interna-tional 44(18) (2018) 22638-22644.

[61] T. Jayaraman, A.P. Murthy, V. Elakkiya, S. Chandrasekaran, P. Nithyadhar-seni, Z. Khan, R.A. Senthil, R. Shanker, M. Raghavender, P. Kuppusami, Recent development on carbon based heterostructures for their applications in energy and 
environment: A review, Journal of Industrial and Engineering Chemistry 64 (2018) 16-59.

[62] H. Li, Y. Zhou, W. Tu, J. Ye, Z. Zou, State-of-the-art progress in diverse het-erostructured photocatalysts toward promoting photocatalytic performance, Ad-vanced Functional Materials 25(7) (2015) 998-1013.

[63] C. Chang, L. Zhu, S. Wang, X. Chu, L. Yue, Novel mesoporous graphite carbon nitride/BiOI heterojunction for enhancing photocatalytic performance under visible-light irradiation, ACS applied materials \& interfaces 6(7) (2014) 50835093.

[64] F. Soleimani, M. Salehi, A. Gholizadeh, Comparison of visible light photo-catalytic degradation of different pollutants by $(\mathrm{Zn}, \mathrm{Mg}) \mathrm{xCu}$-xBi2O4 nanoparticles, Ceramics International 45(7) (2019) 8926-8939.

[65] B. Pant, M. Park, S.-J. Park, H.-Y. Kim, One-pot synthesis of CdS sensitized $\mathrm{TiO} 2$ decorated reduced graphene oxide nanosheets for the hydrolysis of ammo-nia-borane and the effective removal of organic pollutant from water, Ceramics International 42(14) (2016) 15247-15252.

[66] T. Jayaraman, S.A. Raja, A. Priya, M. Jagannathan, M. Ashokkumar, Synthe-sis of a visible-light active $\mathrm{V} 2 \mathrm{O} 5-\mathrm{gC} 3 \mathrm{~N} 4$ heterojunction as an efficient photocata-lytic and photoelectrochemical material, New Journal of Chemistry 39(2) (2015) 1367-1374.

[67] R.A. Senthil, S. Osman, J. Pan, Y. Sun, T.R. Kumar, A. Manikandan, A facile hydrothermal synthesis of visible-light responsive BiFeWO6/MoS2 composite as superior photocatalyst for degradation of organic pollutants, Ceramics Internation-al 45(15) (2019) 18683-18690.

[68] H. Shi, J. Chen, G. Li, X. Nie, H. Zhao, P.-K. Wong, T. An, Synthesis and characterization of novel plasmonic $\mathrm{Ag} / \mathrm{AgX}-\mathrm{CNTs}(\mathrm{X}=\mathrm{Cl}, \mathrm{Br}, \mathrm{I})$ nanocomposite photocatalysts and synergetic degradation of organic pollutant under visible light, ACS applied materials \& interfaces 5(15) (2013) 6959-6967.

[69] D. Yue, D. Chen, Z. Wang, H. Ding, R. Zong, Y. Zhu, Enhancement of visi-ble photocatalytic performances of a $\mathrm{Bi} 2 \mathrm{MoO} 6-\mathrm{BiOCl}$ nanocomposite with plateon-plate heterojunction structure, Physical Chemistry Chemical Physics 16(47) (2014) 26314-26321

[70] S.B.A. Hamid, T.L. Tan, C.W. Lai, E.M. Samsudin, Multiwalled carbon nano-tube/TiO2 nanocomposite as a highly active photocatalyst for photodegradation of Reactive Black 5 dye, Chinese Journal of Catalysis 35(12) (2014) 2014-2019.

[71] L. Bazli, M. Siavashi, A. Shiravi, A review of carbon nanotube/TiO2 composite prepared via sol-gel method, Journal of Composites and Compounds 1(1) (2019) 1-9.

[72] S. Kumar, B. Kumar, A. Baruah, V. Shanker, Synthesis of magnetically sep-arable and recyclable g-C3N4-Fe3O4 hybrid nanocomposites with enhanced pho-tocatalytic performance under visible-light irradiation, The Journal of Physical Chemistry C 117(49) (2013) 26135-26143.

[73] M. Ahmad, E. Ahmed, Z.L. Hong, X.L. Jiao, T. Abbas, N.R. Khalid, Enhance-ment in visible light-responsive photocatalytic activity by embedding $\mathrm{Cu}$ doped $\mathrm{ZnO}$ nanoparticles on multi-walled carbon nanotubes, Applied Surface Science 285 (2013) 702-712.

[74] W. Tongon, C. Chawengkijwanich, S. Chiarakorn, Visible light responsive $\mathrm{Ag} / \mathrm{TiO} 2 / \mathrm{MCM}-41$ nanocomposite films synthesized by a microwave assisted solgel technique, Superlattices and Microstructures 69 (2014) 108-121.

[75] R. Wang, D. Xu, J. Liu, K. Li, H. Wang, Preparation and photocatalytic prop-erties of CdS/La2Ti2O7 nanocomposites under visible light, Chemical Engineering Journal 168(1) (2011) 455-460.

[76] M. Zhu, P. Chen, M. Liu, Graphene oxide enwrapped Ag/AgX (X= Br, Cl) nanocomposite as a highly efficient visible-light plasmonic photocatalyst, Acs Nano 5(6) (2011) 4529-4536.

[77] Y.C. Zhang, Z.N. Du, K.W. Li, M. Zhang, D.D. Dionysiou, High-performance visible-light-driven $\mathrm{SnS} 2 / \mathrm{SnO} 2$ nanocomposite photocatalyst prepared via in situ hydrothermal oxidation of SnS2 nanoparticles, ACS applied materials \& interfaces 3(5) (2011) 1528-1537.

[78] L. Dong, S. Tang, J. Zhu, P. Zhan, L. Zhang, F. Tong, Photoactivated route and new bromine source for $\mathrm{AgBr} / \mathrm{Ag}$ nanocomposites with enhanced visible light photocatalytic activity, Materials Letters 91 (2013) 245-248.

[79] C. Piewnuan, J. Wootthikanokkhan, P. Ngaotrakanwiwat, V. Meeyoo, S. Chi-arakorn, Preparation of TiO2/(TiO2-V2O5)/polypyrrole nanocomposites and a study on catalytic activities of the hybrid materials under UV/Visible light and in the dark, Superlattices and Microstructures 75 (2014) 105-117.

[80] Y. Gu, M. Xing, J. Zhang, Synthesis and photocatalytic activity of graphene based doped TiO2 nanocomposites, Applied Surface Science 319 (2014) 8-15.
[81] C. Pakula, V. Zaporojtchenko, T. Strunskus, D. Zargarani, R. Herges, F. Faupel, Reversible light-controlled conductance switching of azobenzene-based metal/polymer nanocomposites, Nanotechnology 21(46) (2010) 465201.

[82] E. Asadi, A. Fassadi Chimeh, S. Hosseini, S. Rahimi, B. Sarkhosh, L. Bazli, R. Bashiri, A.H. Vakili Tahmorsati, A review of clinical applications of graphene quantum dot-based composites, Journal of Composites and Compounds 1(1) (2019) 31-40.

[83] X. Liu, H.-J. Liu, F. Cheng, Y. Chen, Preparation and characterization of multi stimuli-responsive photoluminescent nanocomposites of graphene quantum dots with hyperbranched polyethylenimine derivatives, Nanoscale 6(13) (2014) 74537460.

[84] Z. Ren, J. Zhang, F.-X. Xiao, G. Xiao, Revisiting the construction of graphene-CdS nanocomposites as efficient visible-light-driven photocatalysts for selective organic transformation, Journal of Materials Chemistry A 2(15) (2014) 5330-5339.

[85] J. Rodríguez-Fernández, M. Fedoruk, C. Hrelescu, A.A. Lutich, J. Feldmann, Triggering the volume phase transition of core-shell Au nanorod-microgel nano-composites with light, Nanotechnology 22(24) (2011) 245708.

[86] H. Kong, J. Song, J. Jang, Photocatalytic antibacterial capabilities of TiO2biocidal polymer nanocomposites synthesized by a surface-initiated photopoly-merization, Environmental science \& technology 44(14) (2010) 5672-5676.

[87] J.Y. Woo, K. Kim, S. Jeong, C.-S. Han, Enhanced photoluminance of layered quantum dot-phosphor nanocomposites as converting materials for light emitting diodes, The Journal of Physical Chemistry C 115(43) (2011) 20945-20952.

[88] J. Choi, M.-J. Choi, J.-K. Yoo, W.I. Park, J.H. Lee, J.Y. Lee, Y.S. Jung, Local-ized surface plasmon-enhanced nanosensor platform using dual-responsive poly-mer nanocomposites, Nanoscale 5(16) (2013) 7403-7409.

[89] P. Chaengchawi, K. Serivalsatit, P. Sujaridworakun, Synthesis of visible-light responsive $\mathrm{CdS} / \mathrm{ZnO}$ nanocomposite photocatalysts via simple precipitation method, Key Engineering Materials, Trans Tech Publ, 2014, pp. 224-229.

[90] A. Haghighatzadeh, M. Hosseini, B. Mazinani, M. Shokouhimehr, Improved photocatalytic activity of $\mathrm{ZnO}-\mathrm{TiO} 2$ nanocomposite catalysts by modulating $\mathrm{TiO} 2$ thickness, Materials Research Express 6(11) (2019) 115060

[91] T.-H. Kim, Y.-H. Jo, G. Gyawali, R. Adhikari, T. Sekino, S.-W. Lee, Synthesis of $\mathrm{TiO} 2-x \mathrm{xy} / \mathrm{Ag}-\mathrm{PbMoO} 4$ nanocomposites: An effective approach for photoinac-tivation of green tide under simulated solar light, Materials Letters 101 (2013) 99-102.

[92] M. Pirhashemi, A. Habibi-Yangjeh, Ultrasonic-assisted preparation of plas-monic $\mathrm{ZnO} / \mathrm{Ag} / \mathrm{Ag} 2 \mathrm{WO} 4$ nanocomposites with high visible-light photocatalytic performance for degradation of organic pollutants, Journal of colloid and interface science 491 (2017) 216-229.

[93] K. Saravanakumar, M.M. Ramjan, P. Suresh, V. Muthuraj, Fabrication of highly efficient visible light driven $\mathrm{Ag} / \mathrm{CeO} 2$ photocatalyst for degradation of or-ganic pollutants, Journal of Alloys and Compounds 664 (2016) 149-160.

[94] J. Ahmad, K. Majid, Enhanced visible light driven photocatalytic activity of CdO-graphene oxide heterostructures for the degradation of organic pollutants, New Journal of Chemistry 42(5) (2018) 3246-3259.

[95] Z. Behzadifard, Z. Shariatinia, M. Jourshabani, Novel visible light driven $\mathrm{CuO} / \mathrm{SmFeO} 3$ nanocomposite photocatalysts with enhanced photocatalytic activi-ties for degradation of organic pollutants, Journal of Molecular Liquids 262 (2018) 533-548.

[96] L. Gan, L. Xu, K. Qian, Preparation of core-shell structured CoFe2O4 incor-porated $\mathrm{Ag} 3 \mathrm{PO} 4$ nanocomposites for photocatalytic degradation of organic dyes, Materials \& Design 109 (2016) 354-360.

[97] M. Mousavi, A. Habibi-Yangjeh, M. Abitorabi, Fabrication of novel magnet-ically separable nanocomposites using graphitic carbon nitride, silver phosphate and silver chloride and their applications in photocatalytic removal of different pollutants using visible-light irradiation, Journal of colloid and interface science 480 (2016) 218-231.

[98] F.A. Hezam, O. Nur, M.A. Mustafa, Synthesis, structural, optical and magnet-ic properties of $\mathrm{NiFe} 2 \mathrm{O} 4 / \mathrm{MWCNTs} / \mathrm{ZnO}$ hybrid nanocomposite for solar radiation driven photocatalytic degradation and magnetic separation, Colloids and Surfaces A: Physicochemical and Engineering Aspects 592 (2020) 124586.

[99] A. Paul, S.S. Dhar, Construction of hierarchical MnMoO4/NiFe2O4 nanocom-posite: Highly efficient visible light driven photocatalyst in the degradation of dif-ferent polluting dyes in aqueous medium, Colloids and Surfaces A: Physicochem-ical and Engineering Aspects 585 (2020) 124090.

[100] H. Hitha, A. Jose, M. John, T. Varghese, Structural and optical modification 
of NiWO4 - Formation of NiWO4/SnPc nanocomposite for improved photocatalyt-ic activity, Materials Chemistry and Physics 239 (2020) 122080.

[101] M.M. Gui, S.-P. Chai, B.-Q. Xu, A.R. Mohamed, Enhanced visible light re-sponsive MWCNT/TiO2 core-shell nanocomposites as the potential photocat- alyst for reduction of $\mathrm{CO} 2$ into methane, Solar Energy Materials and Solar Cells 122 (2014) 183-189.

[102] C. Alvarez-Lorenzo, L. Bromberg, A. Concheiro, Light-sensitive intelligent drug delivery systems, Photochemistry and photobiology 85(4) (2009) 848-860. 